\title{
Os discursos e as controvérsias da cooperação técnico-militar e técnico-policial entre Portugal, Angola e Brasil
}

\author{
The discourses and the controversies on the technical \\ military and technical police cooperation among Portugal, \\ Brazil and Angola
}

\author{
MÓNICA DE MELO FREITAS' \\ monicaflul@hotmail.com \\ GALILEU - REVISTA DE DIREITO E ECONOMIA - e-ISSN 2184-1845 \\ Volume XX $\cdot 1^{\text {st }}$ January Janeiro - 30 ${ }^{\text {TH }}$ June Junho $2019 \cdot$ pp. 59-77 \\ DOI: ??? \\ Submitted on February $12^{\text {th }}, 2019 \cdot$ Accepted on May $28^{\text {th }}, 2019$ \\ Submetido em 12 de Fevereiro, 2019 . Aceite a 28 de Maio, 2019
}

RESUMO O presente artigo propõe-se analisar a atividade de cooperação técnico-militar e técnico-policial, com base nos fundamentos de análise da sociologia pragmática. Acreditamos que o estudo dos objetivos que os diferentes atores atribuem à cooperação constitui um elemento-base para a compreensão da referida cooperação no espaço lusófono. Ao contrário de autores como (Moreira, 2001), tentaremos enquadrar o nosso estudo na transformação do sistema capitalista do Estado-Providência, pelo facto de acreditarmos que as alterações nos moldes como os atores realizam os seus julgamentos, principalmente no sector da Segurança, poderão compreender uma estratégia muito mais vasta, relacionada à legitimação do estado-providência e à sobrevivência do próprio sistema capitalista.

RECORREU-SE à metodologia de análise compreensiva e a um conjunto de técnicas qualitativas de análise de dados, pelo facto de pretendemos analisar materiais densos no que concerne à sua subjetividade. A grelha taxonómica de (Boltanski \& Thèvenot, 1991) servirá de suporte ao estudo que pretendemos desenvolver, visto colocar ao nosso dispor um conjunto de ferramentas para análise das lógicas de justificação formuladas pelos atores, quando estes se encontram em situações de controvérsia pública

Posto isto, sublinhamos que este estudo tem a pertinência científica de contribuir para a compreensão dos moldes como os diferentes atores do sector da Segurança formulam os

1 Investigadora Doutorada Integrada do Centro Interdisciplinar de Ciências Sociais da Universidade Nova de Lisboa (CICS Nova/UNL). 
julgamentos quando são confrontados. A par disto, apresenta a pertinência prática de dar a conhecer como as instituições de Segurança gerem as diferentes lógicas de julgamento e ainda de que forma conseguem reunir os consensos e formalizar os compromissos.

IMPORTA, precisamente, tentarmos perceber se a reunião de consensos depende ou não da articulação das diferentes lógicas, sob a alçada de um princípio superior de bem comum e, em caso afirmativo, como isto ocorre.

PALAVRAS-CHAVE: Controvérsias, Cooperação Técnico-Policial, Países Lusófonos.

ABSTRACT This paper aims to analyze the activity of cooperation in police sector through application of concepts and techniques of pragmatic sociology. In our mind, the study of the individual objectives negotiated about the cooperation became crucial to its comprehension especially in the Lusophone region.

CONTRARILY to authors as (Moreira, 2001), we are trying to discuss the object into the context of transformation of Providence State and Capitalist Model. In our mind, the judgements created by the institutions and actors of police sector aiming in contributing to legitimation of providence state and capitalist system.

THE study applied the model of comprehensive analyze and the qualitative techniques of analyze because most of data available were very density in subjectivity. The matrix of the justification' logics proposed by Boltanski \& Thèvenot (1991) have supported the treatment process of data. This theory showed be the most adjusted because allows identifying and analyzing the individual justifications created in controversial situations.

THE scientific pertinence of this study is essentially to try to contribute to comprehension of how actors build their judgements when are confronted through analyzing of police sector. In practical way, this study highlights how institutions and actors manage different justification logics; how they achieve consensus and make agreements.

IN sum, we are searching to understand if achieving consensus in this sector results or not of managing of different justification logics. In affirmative case, if are evoked superior principles of common good and how it occurs.

KEYworDs: Controversies, Technical Police Cooperation, Lusophone Countries.

\section{Definições iniciais}

O presente artigo resulta de uma investigação realizada sobre a cooperação técnico- policial lusófona e compreende-essencialmente duas fases distintas.

A primeira fase perspectiva uma análise científica e diz respeito à compreensão dos argumentos invocados pelos atores, quando confrontados publicamente sobre o tema do reforço dos acordos de cooperação em matéria de Segurança entre os países do espaço lusófono. 
Os discursos e as controvérsias da cooperação técnico-militar e técnico-policial entre Portugal, Angola e Brasil MÓNICA DE MELO FREITAS

GALILEU · e-ISSN 2184-1845 - Volume XX - Issue Fascículo 1 $1^{\text {st }}$ January Janeiro $-30^{\text {th }}$ June Junho 2019 - pp. 59-77

Importa precisamente constatar se existem controvérsias nas intenções no seio do sector da Segurança, quanto ao reforço da cooperação técnico-policial e, caso existam, de que forma coexistem atores com diferentes lógicas debaixo da alçada de um princípio superior de bem comum. Segundo Boltanski e Thévénot ${ }^{2}$, a formalização de compromissos entre atores com sentidos distintos, só ocorre quando se consegue congregar as diversidades dentro de uma lógica superior de bem comum socialmente legítima, em termos de generalidade.

A cooperação técnico-policial engloba vários domínios, entre outros, a consolidação de acordos de cooperação ao nível formal/institucional e informal/interpessoal entre instituições e atores com responsabilidades na área da segurança, com vista potenciar o intercâmbio de informação e conhecimento; o benchmarking das melhores práticas levadas a cabo no âmbito da segurança rodoviária, ordem pública, violência doméstica, combate à imigração ilegal; a externalização de competências técnicas relacionadas com a manutenção da ordem pública em grandes eventos desportivos; a realização de exercícios conjuntos entre forças de segurança de diferentes países; o intercâmbio de oficiais para a realização de formação noutro país lusófono; a integração de elementos das forças de segurança em equipas multidisciplinares de investigação em Ciências Policiais e a participação conjunta em missões humanitárias e de Apoio à Paz, levadas a cabo sob a égide das Nações Unidas.

A segunda fase deste projeto relaciona-se com a análise dos modelos de reunião de consensos e de formalização de compromissos, levados a cabo pelas instituições da Segurança de Angola, do Brasil e de Portugal.

A compreensão dos modelos de formalização de compromissos em instituições ligadas à Segurança e posteriormente à Defesa tem como mais-valia o facto de se tratar de instituições representativas de direitos fundamentais consagrados na Carta Universal dos Direitos do Homem.

A Segurança, num sentido mais lato, corresponde a um dos direitos fundamentais contemplados na Carta Universal dos Direitos do Homem (artigo n. ${ }^{\circ}$ 3, Publicada no Diário da República, I Série A, n. ${ }^{\circ}$ 57/78, de 9 de Março de 1978) e na Constituição da República Portuguesa (artigo n. ${ }^{\circ}$ 27, VII Revisão Constitucional, 2005).

Como ponto de partida para a análise tomam-se as instituições de Segurança e Defesa de Angola, Brasil e Portugal, pelo facto de serem as nações que apresentam presentemente os maiores níveis de desenvolvimento económico, científico, tecnológico e militar no

2 BOLTANSKI, L.; THÉVENOT, L. - De La Justification. Les Économies de La Grandeur. Paris: Éditions Gallimard, 1991. 
espaço da Lusofonia ${ }^{3}$. Segundo Moreira, a escassez de recursos financeiros, tecnológicos e científicos faz com que países como Cabo Verde, Guiné Bissau, Moçambique, São Tomé e Príncipe e Timor Leste, assumam, na prática, um patamar menos proeminente na negociação. ${ }^{4}$ Contudo, numa fase posterior da investigação, tencionamos expandir o nosso foco de investigação à globalidade dos países lusófonos.

$\mathrm{O}$ artigo em apreço tem a pertinência científica de tentar compreender o processo de construção de julgamentos em situações de confrontação pública, num sector com funções de destaque para a produção de um sentimento de segurança dos cidadãos e para a salvaguarda dos direitos de cidadania contemplados na Carta Universal dos Direitos do Homem. Além disso, os sectores da Defesa e Segurança são encarados como pilares da soberania dos Estados nas sociedades contemporâneas. ${ }^{5}$

Quanto à sua pertinência prática, acreditamos que a análise dos modelos de formalização de compromissos no sector da Segurança, apresentam a mais-valia de poderem futuramente auxiliar tanto as instituições públicas, como as privadas e organizações não-governamentais, nos processos de mobilização social envolvendo atores deste sector.

A originalidade deste estudo incide essencialmente na análise comparativa dos modelos de processamento dos julgamentos e formalização de compromissos, levados a cabo em instituições ligadas à Segurança.

Para realizar esta investigação, apoiamo-nos na metodologia compreensiva, pelo facto de considerarmos os sentidos atribuídos pelos atores como sendo materiais privilegiados para análise.

\section{Questões de partida}

Como foi anteriormente referido, o objetivo deste artigo consiste em procurar nas abordagens teóricas existentes, que versam a cooperação entre os países lusófonos na área técnico-policial, bem como através de entrevistas exploratórias realizadas, o levantamento de insights que nos possibilitem sustentar cientificamente e empiricamente o estudo que pretendemos desenvolver.

Este artigo será consubstanciado à compreensão da forma como os atores dos segmentos diplomático, estratégico e técnico-operacional formulam os seus julgamentos

\footnotetext{
3 Lusofonia: termo utilizado para se referir ao conjunto de países que possuem a Língua Portuguesa como língua oficial. Ex.: Angola, Brasil, Cabo Verde, Guiné-Bissau, Moçambique, Portugal, São Tomé e Príncipe e Timor Leste. 4 MOREIRA, Adriano - Comunidade dos Países de Língua Portuguesa. Cooperação. Lisboa: Almedina, 2001. 5 MOREIRA, Adriano - Comunidade dos Países de Língua Portuguesa. Cooperação. Lisboa: Almedina, 2001.
} 
sobre os acordos de cooperação estabelecidos na área técnico-militar e técnico-policial, direcionando-se esta análise principalmente para os casos de Angola, Brasil e Portugal.

Constitui ainda objetivo deste estudo, analisar os modelos de obtenção de consensos e formalização de compromissos entre atores com diferentes julgamentos, dentro das instituições da Segurança nos países em análise.

As questões de partida que servem de suporte à investigação que nos propomos realizar são as seguintes:

- Até que ponto o contexto histórico, cultural e linguístico, propicia o reforço dos acordos de cooperação técnico-policial entre os países lusófonos?

- Em que medida a CPLP representa uma mais-valia ao reforço da referida cooperação?

- Em que medida as transformações estruturais que vêm ocorrendo no interior do sistema capitalista provocaram alterações nas práticas gestionárias levadas a cabo na área da Segurança?

- Até que ponto os valores pessoais dos dirigentes influenciam o reforço da cooperação na área descrita?

- Qual é a visão de médio e longo prazo para o reforço da cooperação em Segurança?

- Que tipos de dificuldades ocorrem durante o processo?

- Quais são as ferramentas empregues na resolução destas dificuldades?

- Em que medida as ferramentas empregues são de origem mais ou menos institucionalizada?

Qual é o papel das redes informais de cooperação no processo do reforço da cooperação? Após a realização de algumas leituras foi possível constatar que os autores que abordam a temática da cooperação entre os países lusófonos, inclusive na área da Segurança, privilegiam enquadramentos teóricos bastante díspares. Enquanto Moreira ${ }^{6}$ sustenta uma abordagem essencialmente histórica, já Bernadino ${ }^{7}$ apresenta uma abordagem essencialmente política.

Em nosso entender, a compreensão do fenômeno da cooperação em matéria de Segurança deverá também ser analisada do ponto de vista das transformações que estão a ocorrer no interior do sistema capitalista e da migração de práticas gestionárias do sector privado para o sector público.

6 MOREIRA, Adriano - Comunidade dos Países de Língua Portuguesa. Cooperação. Lisboa: Almedina, 2001.

7 Em CPLP - Construindo a Comunidade. Europress: Lisboa, 2008. 
Constata-se que as instituições públicas, para se legitimarem, estão a ser cada vez mais constrangidas a justificarem também a sua ação com base em critérios de eficiência próprios do sector privado. ${ }^{8}$

Tencionamos certificar se este enquadramento faz ou não sentido, a partir da análise documental às bibliografia da especialidade, aos documentos político-normativos de regulação do sector da Segurança e através de entrevistas exploratórias realizadas a atores com cargos de decisão nos segmentos diplomático, estratégico e técnico-operacional.

\section{Enquadramento teórico:}

\section{A. As transformações do sistema capitalista e as alterações nas formas de justificação}

Segundo Boltanski e Chiapello ${ }^{9}$, as transformações ocorridas no interior do sistema capitalista requerem a adaptação das justificações, dos dispositivos (formas utilizadas para responder às críticas) e das provas, ao novo contexto institucional que se vive, visando com isto a legitimação do próprio sistema da acção $0^{10}$.

Em detrimento disso, partimos da definição de agente como aquele que utiliza um conjunto de valores morais na critica das suas ações e das ações dos outros, logo, sendo dotado de capacidade reflexiva. Posto isto, questionamo-nos até que ponto o processo da crítica resultou da criação de novos dispositivos de legitimação social, nas instituições ligadas à Segurança no espaço lusófono?

Para Boltanski \&e Chiapello" , o espírito do capitalismo incorpora uma dimensão moral que confere uma justificação às pessoas para aderirem voluntariamente ao modo de vida capitalista, perpetuando desta forma o capitalismo, por meio da sua revisão crítica e transformação permanente. Contudo, o abrandamento conjuntural e a incerteza estrutural que se abateram sobre o ritmo de crescimento económico, após um período de estagnação económica, acrescidos de outros fatores de ordem social e ética, minaram estruturalmente a sustentabilidade dos regimes de Estado-Providência (alterações demográficas; envelheci-

8 SILVESTRE, Hugo Marco C.; ARAÚJO, Joaquim Filipe F. E. - A gestão por Resultados no Sector Público: O caso dos Hospitais EPE, 2005. [Consultado em: Março de 2019]. Disponível em: https://www.repository.utl.pt/ bitstream/10400.5/515/4/605.pdf.

9 BOLTANSKI, L.; CHIAPELLO, E. - O Novo Espírito do Capitalismo. 1. ${ }^{\text {a }}$ ed. São Paulo: Martins Fontes, 2009.

10 VENTURA, Elvira - Estudo da Responsabilidade Social no Campo das Organizações Bancárias. EBAPE (Escola Brasileira de Administração Pública e de Empresas). Tese apresentada à EBAPE para a obtenção do grau de doutor, 2005, p. 32; BOLTANSKI, L.; CHIAPELLO, E. - O Novo Espírito do Capitalismo. 1. ${ }^{\text {a }}$ ed. São Paulo: Martins Fontes, 2009.

11 BOLTANSKI, L.; CHIAPELLO, E. - O Novo Espírito do Capitalismo. 1. ${ }^{a}$ ed. São Paulo: Martins Fontes, 2009. 
mento e rácios de dependência; limites à fiscalidade sobre os lucros e o capital em contexto de globalização; declínio do modelo de produção fordista e da composição social das classes assalariadas, no capitalismo pós-industrial $)^{12}$.

A crise de sustentabilidade financeira e política do Estado-Providência obrigou a reajustamentos políticos e financeiros, que têm levado à restrição de garantias públicas de direitos sociais, à transferência de parte dessas responsabilidades para o sector privado, à exigência de maior eficiência na aplicação dos recursos pelo sector público e à consolidação de alianças envolvendo o sector público, privado e ONGs, com vista a resgatar a legitimidade do Estado-Providência e assegurar a manutenção do próprio capitalismo.

Por um lado, a escassez de recursos financeiros para investimento e, por outro, o aumento da pressão sobre as instituições públicas, com vista a obrigá-las atuar segundo princípios de governação mais eficazes, levaram-nas a enveredar pelos paradigmas que fundamentam o New Public Management.

Este compreende um novo modelo de gestão, onde princípios como a participação coletiva e a transparência de processos constituem elementos-chave. O New Public Management compreende o conjunto de ferramentas de gestão destinadas a serem utilizadas pelas instituições públicas, com vista alcançar os objetivos de participação coletiva e de transparência de processos. ${ }^{13}$

Neste sentido, levantamos a questão, até que ponto o envolvimento do sector da Segurança, em redes de cooperação, poderá contribuir para legitimidade das forças policiais?

Partimos da hipótese de que esta crise de legitimidade constitui uma via para compreender as transformações que vêm ocorrendo no interior das instituições públicas ligadas à Segurança. Principalmente porque constatamos que tem havido mudanças nas lógicas de justificação apresentadas pelos atores ligados a estes sectores na arena pública. Acreditamos que as referidas alterações poderão estar enquadradas na estratégia de legitimação do Estado Social na contemporaneidade.

\section{B. Reflexão analítica sobre as perspetivas teóricas desenvolvidas em torno da cooperação lusófona}

Começamos por esclarecer o contexto histórico e geopolítico em que normalmente os estudos relacionados com a cooperação entre os países lusófonos se baseiam. No que concerne

12 TRIGILIA, Carlo - Economic Sociology: State, Market, and Society in Modern Capitalism. Oxford: Blackwell Publishers, 2002, p. 172; e Esping-Andersen apud TRIGILIA, Carlo - Economic Sociology: State, Market, and Society in Modern Capitalism. Oxford: Blackwell Publishers, 2002, p. 88.

13 EWALT, Jo Ann G. - Theories of Governance and New Public Management: Links to Understanding Welfare Policy Implementation. Eastern Kentuchky University. Newark, 2001. 
aos países lusófonos, ou seja, países que outrora fizeram parte do império colonial português, com traços sociais, culturais e linguísticos próprios e que se mantiveram ao longo do tempo, pode-se dizer que o processo de colonização e descolonização ocorreu de forma distinta em cada um destes países, ou seja, Angola, Brasil, Cabo Verde, Guiné-Bissau, Moçambique, São Tomé e Príncipe e Timor Leste.

As condições em que se verificou o processo de colonização e descolonização do Brasil, por exemplo, não voltaram a repetir-se em nenhuma outra ex-colónia portuguesa. Segundo Moreira $^{14}$, entre Brasil e Portugal sempre houve uma relação afetiva bastante forte.

Embora tenha sempre existido uma densa relação de cordialidade e de afetividade entre Brasil e Portugal, esta relação nem sempre foi consensual. Atores da sociedade civil e artística brasileira realizaram inúmeras iniciativas com vista a fomentar o esquecimento da época colonial no Brasil, entre os quais se sublinha Darcy Ribeiro. ${ }^{15}$

Além destas iniciativas de âmbito civil, os ministérios dos negócios estrangeiros de ambos os países estiveram durante algum tempo de costas voltadas um para outro, essencialmente até meados do século XX, ou seja, entre 1890 e 1940. Apesar de existirem estas dualidades, houve ao longo deste período inúmeras visitas de cortesia de Chefes-de-Estado brasileiros a Portugal como de portugueses ao Brasil.

A dualidade amor/ódio que sempre existiu na relação Brasil-Portugal, contribuiu fortemente para a consolidação de um espírito ideológico-político de repulsa à dominação colonizadora de Portugal, principalmente no ano de 1955 quando a ONU (Organização das Nações Unidas) repreendeu Portugal pelo facto de continuar a manter o império ultramarino.

Quanto à relevância da língua portuguesa para a coesão dos países lusófonos ao nível das estratégias político-económicas, pudemos constatar que as transações financeiras que os países lusófonos estabelecem entre si, ocorrem em menor número quando comparadas com as transações que estes realizam com outros países exteriores ao espaço lusófono. ${ }^{16}$

Portugal tem representado uma porta de entrada para as mercadorias exportadas pelos Países de Língua Oficial Portuguesa PALOP para a Europa. Contudo, esta porta poderá deixar de fazer sentido quando estes países passarem a integrar a Organização Mundial do Livre Comércio. ${ }^{17}$

A relação que Portugal mantém hoje com os países africanos está fortemente marcada pela transferência de recursos, tecnologias e know-how, com vista a potenciar o desenvolvimento econômico, social e democrático destes países.

14 MOREIRA, Adriano - Comunidade dos Países de Língua Portuguesa. Cooperação. Lisboa: Almedina, 2001. 15 MOREIRA, Adriano - Comunidade dos Países de Língua Portuguesa. Cooperação. Lisboa: Almedina, 2001. 16 MOREIRA, Adriano - Comunidade dos Países de Língua Portuguesa. Cooperação. Lisboa: Almedina, 2001 17 MOREIRA, Adriano - Comunidade dos Países de Língua Portuguesa. Cooperação. Lisboa: Almedina, 2001. 
Pelo que pudemos perceber, desde meados da década de 70 para cá, Portugal tem vindo a fazer por estes países aquilo que não conseguiu durante séculos de domínio colonial. A questão que se coloca é, até que ponto os recursos que Portugal está a transferir para estes países potenciam efetivamente o seu desenvolvimento? O que é que Portugal entende por desenvolvimento e o que pretende com o desenvolvimento dos países africanos? Até que ponto o investimento nestes países não está relacionado com uma necessidade de Portugal ultrapassar traumas de um passado colonial ainda presente na memória de algumas gerações? O que representa para os países africanos o incentivo ao desenvolvimento fornecido por Portugal? Até que ponto os países africanos vêm neste incentivo uma forma de desenvolverem competências de racionalidade crítica e uma oportunidade de autonomização?

Com vista consolidar estratégias comuns de desenvolvimento social, científico, cultural e econômico entre os países da Lusofonia, foi criada a 26 de Julho de 1997 a CPLP - Comunidade dos Países de Língua Portuguesa.

Esta comunidade tem como objetivos, essencialmente: fomentar o fortalecimento e a promoção da língua e cultura lusófona no mundo; promover o intercâmbio de conhecimento, tecnologias e profissionais talentosos entre os países; incentivar as transações comerciais entre os estados membros; além de procurar elevar o nível de desenvolvimento institucional, econômico, científico, social e cultural dos países africanos e de Timor-Leste. Esta comunidade compreende os países que compõem a Lusofonia, ou seja, Angola, Brasil, Cabo Verde, Guiné-Bissau, Moçambique, Portugal e Timor-Leste.

Para muitos autores, como Moreira ${ }^{18}$ e Bernadino ${ }^{19}$, os resultados alcançados pela CPLP são ainda incipientes. Poderá dizer-se que a CPLP ainda não conseguir delinear uma estratégia de coesão e de desenvolvimento econômico, social e cultural adequada às necessidades de cada um dos países.

De acordo com Moreira $^{20}$, a CPLP precisa englobar na sua estratégia de mobilização, os interesses particulares de cada um dos seus estados-membros. A CPLP necessita ainda encontrar formas de integrar os interesses estratégicos dos blocos regionais nos quais os seus estados-membros estão inseridos, com vista a ser mais competitiva (ex.: MERCOSUL, ao qual se encontra associado o Brasil; CEDEAO - Comunidade Económica dos Estados da África Ocidental, à qual estão associados alguns países africanos tais Cabo Verde e Guiné-Bissau; SADC - Comunidade para o Desenvolvimento da África Austral, à qual se encontra associada Angola e a União Europeia, à qual se encontra associado Portugal).

18 MOREIRA, Adriano - Comunidade dos Países de Língua Portuguesa. Cooperação. Lisboa: Almedina, 2001. 19 Em CPLP - Construindo a Comunidade. Europress: Lisboa, 2008.

20 MOREIRA, Adriano - Comunidade dos Países de Língua Portuguesa. Cooperação. Lisboa: Almedina, 2001. 
Não se pretende desvalorizar as perspetivas teóricas que apontam os resquícios da época colonial, ou as diferentes opções estratégicas levadas a cabo pela CPLP, como fatores condicionadores do reforço dos acordos de cooperação no espaço lusófono. Acreditamos, contudo, que a chave para a compreensão do fenómeno da cooperação lusófona, inclusive na área da Segurança, poderá passar pela análise das mudanças nos modelos de gestão que vêm ocorrendo nas organizações deste sector, fruto das transformações ocorridas no interior do sistema capitalista e da migração das práticas do sector privado para o sector público.

Os atores e as organizações têm sido cada vez mais confrontados com a necessidade de terem que justificar as ações que desenvolvem segundo critérios superiores de bem-comum, para serem socialmente aceites.

A par destas alterações, tem vinda a institucionalizar-se a crítica como instrumento de mudança social. Logo, com vista, a reunir o maior número de consensos e de compromissos em torno de princípios superiores comuns, as organizações, tanto públicas como privadas, têm vindo a apostar cada vez mais no estabelecimento de redes de cooperação. Neste sentido, mais do que uma questão de identidade, a formalização de redes de cooperação tem representado um dispositivo crucial de legitimação da ação social, inclusive no sector da Segurança. Como exemplo disso recorda-se que no Programa Prós e Contras, transmitido pela RTP, no dia 23/01/12, o Ministro da Administração Interna de Portugal admitiu que a articulação das polícias em rede é crucial, numa altura em que os recursos são cada vez mais escassos.

A par disso, constata-se que são cada vez mais frequentes as críticas realizadas nos meios de comunicação social portuguesa por representantes da sociedade civil, apontando a necessidade de coordenação entre as diferentes polícias. Posto isto, acreditarmos que a forma como os atores do sector da Segurança julgam o trabalho em rede tanto poderá facilitar como condicionar a cooperação.

\section{Boletim Histórico e Estratégico da Cooperação Técnico-Policial}

Em Moreira ${ }^{21}$ podemos constatar que as iniciativas governamentais de estruturação da cooperação entre Portugal e as ex-colónias intensificaram-se a partir do ano de 1974. Em 31 de Dezembro de 1974 foi criado o gabinete coordenador para cooperação, sob a tutela da presidência da república. Nesta altura, o referido gabinete ocupava-se de todos os acordos da cooperação, inclusive na áreas da Segurança e Defesa. 
Os discursos e as controvérsias da cooperação técnico-militar e técnico-policial entre Portugal, Angola e Brasil MÓNICA DE MELO FREITAS

GALILEU - e-ISSN 2184-1845 - Volume XX - Issue Fascículo 1 - 15t January Janeiro - 30 th June Junho $2019 \cdot \mathrm{pp} .59-77$

Em Julho de 1977, a centralização e coordenação da cooperação, ao nível das forças armadas, foram atribuídas ao Chefe do Estado-Maior-General das Forças Armadas (CEMG-FA). Em Portugal, durante cerca de 3 anos, a cooperação foi coordenada pelo gabinete para a cooperação, depois pelo Ministério da Cooperação e a seguir pelo Ministério dos Negócios Estrangeiros. Só a partir de 1977 é que a cooperação começou a apresentar contornos de planeamento estratégico diferenciado.

Em Maio de 1983, foi emitido um despacho conjunto, envolvendo os Ministérios da Defesa Nacional e dos Negócios Estrangeiros (MDN-MNE), no qual o MNE passava a ser o órgão coordenador da política de cooperação, principalmente técnico-militar, no quadro genérico da cooperação entre Portugal e os PALOP. Contudo, as ações a desenvolver deveriam obter uma autorização prévia, através do despacho conjunto dos ministros da defesa nacional e dos negócios estrangeiros.

O ano de 1985 viria a ser marcado pelo aumento do número de pedidos de cooperação, essencialmente militar, por parte dos PALOP. Durante os anos de 1988 e 1989, foram assinados acordos de cooperação técnico-militar entre Portugal e Cabo Verde, Portugal e Guiné Bissau e Portugal e São Tomé e Príncipe. Portugal criou, em Julho de 1989, a Direção Geral de Política Nacional de Defesa (DGPN), com o objetivo de unificar por um lado as ações, no âmbito da cooperação técnico-militar, levadas a cabo pelo Ministério dos Negócios Estrangeiros, Estado-Maior-General das Forças Armadas e Ministério da Defesa Nacional MDN e, por outro, alcançar ganhos de eficiência a partir da centralização de processos e uniformização de procedimentos.

Durante o ano de 1990, a DGPN formalizou, no mínimo, três programas-quadro no âmbito da cooperação técnico-militar, envolvendo Portugal e países como Cabo Verde, Guiné-Bissau e Moçambique. Em 1991 foi consolidado um programa-quadro de cooperação técnico-militar com São Tomé e Príncipe. Os programas-quadro são instrumentos de planeamento da cooperação de carácter regular e duradouro.

Em 1996, foi consolidado o primeiro programa-quadro de cooperação técnico-militar envolvendo Portugal e Angola. Constatando-se que a cooperação técnico-militar envolvendo Portugal e Angola deu-se mais tardiamente, quando comparada a outros países dos PALOP, será pertinente interrogarmo-nos até que ponto a manutenção de acordos de cooperação com países da ex-União Soviética estiveram na causa deste retardamento?

Ressalta-se a inexistência de programas-quadro de cooperação envolvendo Portugal e o Brasil. Embora não estivesse claro em (Moreira, 2001) os programas-quadro consolidados entre Portugal e as ex-colónias relacionam-se quase sempre à formação técnico-militar e técnico-policial, à reconstrução de estruturas de apoio à formação nestes países, bem como à assessoria técnica e realização de exercícios conjuntos. Além da cedência de material e 
outros equipamentos militares e policiais por parte de Portugal às ex-colónias, com vista a serem utilizados pelas forças locais.

$\mathrm{Na}$ consulta que realizamos ao site do IPAD Instituto de Apoio ao Desenvolvimento ${ }^{22}$ verificamos que a cooperação entre Portugal e PALOPS Países de Língua Oficial Portugal encontra-se estruturada em Planos Integrados da Cooperação PIC e Planos Anuais da Cooperação. Enquanto o primeiro é programado de três em três anos, o segundo é programado de ano a ano.

Os referidos documentos normativos da cooperação abrangem diversas áreas tais como: Saúde, Educação, Agricultura e Pescas, Energia, Segurança e Defesa. Os montantes e o nível de prioridade de cada uma destas áreas dependem das orientações políticas dos países beneficiários. Enquanto para a Guiné Bissau, a Segurança e a Defesa compreendem as duas áreas mais prioritárias da cooperação, para Moçambique, a formação e a empresarialidade compreendem as áreas com maior nível de importância estratégica.

No que concerne aos montantes envolvidos na cooperação, constatamos que estes não são estáticos porque dependem da disponibilidade financeiras das organizações doadoras como por exemplo, ONU Organização das Nações Unidas, UE), de países doadores tais como Japão, EUA, Brasil, dentre outros.

De modo geral, pode-se dizer que Cabo Verde dispõe do maior montante para financiamento dos projetos de cooperação (173.000.000€), seguido de Moçambique (62.000.000€) e em terceiro lugar Timor Leste (25.000.000€). Cabo Verde dispõe do montante mais elevado, pelo fato de terem sido criadas linhas de crédito com vista a apoiar os planos de cooperação.

Os referidos planos podem contemplar a formalização de acordos de cooperação bilaterais e multilaterais. Os acordos de cooperação bilaterais são geralmente estabelecidos entre Portugal e os países dos PALOP ou Timor Leste. Já nos acordos multilaterais, Portugal participa conjuntamente com outras organizações internacionais (ONU, UE) ou nacionais (ministérios, autarquias, universidades/ centros de investigação, setor privado, ONGs Organizações Não Governamentais) no planeamento, implementação, coordenação e avaliação dos impactes dos projetos levados a cabo ao abrigo da cooperação multilateral.

Quando transferimos o nosso foco de análise à cooperação consolidada nas áreas da Segurança e Defesa entre Portugal e PALOPS/ Portugal e Timor Leste, certificamos que esta tanto pode resultar de acordos bilaterais como multilaterais de cooperação. Os acordos de cooperação bilateral envolvem ocorrem normalmente entre os governos e/ou ministérios homólogos. Já os acordos multilaterais, podem envolver as forças armadas, as polícias de 
segurança pública e de investigação criminal, como também as respectivas instituições de formação militar e policial além dos hospitais militares, dentre outros.

De 2005 para cá, os projetos desenvolvidos nas áreas da Segurança e da Defesa ao abrigo dos Planos Integrados da Cooperação PIC, contemplaram essencialmente a realização de formação técnica - militar e técnico - policial; a assessoria técnica, jurídica, administrativa e logística; treinamentos conjuntos; apoio à reconstrução/ consolidação de novas unidades de apoio ao ensino e/ou à operacionalização das forças militares e policiais; atualização de doutrinas militares e policiais; consolidação de estruturas jurídicas capaz de fornecer o enquadramento legal necessário à ação sustentada das forças armadas e das forças de segurança dos países beneficiários; suporte no fardamento das forças armadas e forças policiais; apoio na consolidação de serviços sociais direcionados aos efetivos das referidas forças de Segurança e Defesa além da prestação de serviços médico - hospitalares aos militares e polícias destes países em Portugal.

Conforme pudemos verificar, inúmeros projetos vêm sendo desenvolvidos ao abrigo da cooperação técnico-militar e técnico-policial consolidada tanto a nível bilateral como multilateral. No entanto, não se consegue perceber a partir da consulta ao site do IPAD, que iniciativas estes projetos desenvolveram no âmbito da formação técnico-militar e técnico-policial, que operações de treinamento foram realizadas, qual foi o número de militares e policiais envolvidos nestas iniciativas, qual é percentagem de formados que concluíram com êxito a formação; quantas ações de assessoria técnica foram realizadas; que impactes as iniciativas desenvolvidas proporcionou às forças armadas e às forças policiais dos países beneficiários; que benefícios estas iniciativas acarretaram para Portugal.

Neste sentido, interrogamos a que se deve a indisponibilidade destas informações visto que cabe ao IPAD o planeamento, a execução, o acompanhamento das iniciativas realizadas, além da avaliação dos impactes e disponibilização destes.

De acordo com o IPAD, os planos integrados da cooperação não tem gerado os resultados esperados por ausência de organização tanto do lado de Portugal como dos países beneficiários. Neste sentido, o próprio IPAD sugere que sejam tomadas medidas no sentido de intensificarem os contactos pessoais entre os representantes governamentais de ambos os países com vista elevar os níveis de eficácia das iniciativas desenvolvidas. O IPAD sugere ainda, que as iniciativas passem a integrar os verdadeiros interesses e necessidades dos países beneficiários com vista contribuírem para a resolução de problemas enfrentados pelas sociedades. Por último, o IPAD faz referência à necessidade de se enviar oficiais de ligação para as embaixadas dos países beneficiários e de envolver os oficiais de ligação no acompanhamento das iniciativas em curso. 
No que concerne à cooperação entre Portugal e Brasil, soube-se através do site do IPAD que esta vem se intensificando de 2007 para cá. Contudo, não foi possível conhecer quais são as áreas abrangidas por esta cooperação; que projetos foram desenvolvidos e quais foram os impactes gerados. A única coisa que constatamos foi que entre 2007 e 2010 os montantes envolvidos na cooperação subiram consideravelmente, dos cerca de 2.000.000€ em 2007 para os 7.000.000€ em 2010.

Em Moreira ${ }^{23}$ pudemos constatar que o Brasil manteve sempre um certo distanciamento em relação à cooperação em Segurança e Defesa, principalmente com Portugal. Pelo que constatamos, este distanciamento pode estar relacionado aos interesses estratégicos que ambos os países mantêm em África.

Portanto, antes de apontar possíveis formas de resolução deste impasse, considera-se importante indagar junto dos atores que dirigem as instituições do sector da Segurança, tanto do Brasil como de Portugal e Angola, por modo a compreender a forma como estes encaram a cooperação técnico-policial; interessa compreender até que ponto consideram pertinente o alargamento da referida cooperação aos demais países lusófonos; em que medida a consolidação e/ou reforço dos acordos de cooperação nestas áreas representam uma mais-valia para o reforço da segurança interna de cada um dos países e da comunidade lusófona no seu todo; quais são as perspetivas de médio e longo prazo para a cooperação técnico-policial lusófona; quais são os fatores que têm constituído dificuldade no reforço da cooperação neste âmbito; que mecanismos poderão ser acionados com vista resolver estes impasses; outros atores da sociedade que consideram pertinente serem envolvidos nesta cooperação.

Ao contrário de autores como Moreira ${ }^{24}$, que tendem a privilegiar abordagens do tipo históricas na compreensão do fenómeno da cooperação lusófona, tencionamos abordar a cooperação técnico-policial entre os países lusófonos, em especial, entre Angola, Brasil e Portugal, do ponto de vista da Sociologia pragmática. Partimos do pressuposto que o reforço dos acordos de cooperação técnico-policial entre os países em análise poderá ser melhor entendido através da análise dos dispositivos de formalização de compromissos entre atores e organizações com julgamentos distintos, no que concerne à cooperação. Na verdade, parece-nos que as instituições com responsabilidades na regulação destes sectores, seja a nível micro ou macro, ainda não conseguiram encontrar uma forma de manter atores com diferentes lógicas de julgamento, articulados sob um mesmo princípio superior comum.

23 MOREIRA, Adriano - Comunidade dos Países de Língua Portuguesa. Cooperação. Lisboa: Almedina, 2001. 24 MOREIRA, Adriano - Comunidade dos Países de Língua Portuguesa. Cooperação. Lisboa: Almedina, 2001. 
De acordo com Boltanski e Thèvenot ${ }^{25}$, a ausência de consensos dificulta o sucesso de qualquer iniciativa. Com vista comprovar esta nossa hipótese, procurou-se compreender, através das entrevistas exploratórias que realizamos aos atores do segmento diplomático, técnico-estratégico e operacional do sector da Segurança, procurando depreender em que estádio de desenvolvimento se encontram os países lusófonos no domínio da cooperação técnico-policial e em que medida os atores consideram pertinentes estes acordos de cooperação.

\section{Enquadramento metodológico: Metodologia de análise compreensiva}

Baseamo-nos na metodologia de análise compreensiva para desenvolver o presente estudo, dando um especial enfoque à análise dos processos de julgamento realizados em situações de controvérsia pública, tal como aos moldes de formalização de consensos com base em Boltanski e Thèvenot ${ }^{26}$.

A teoria proposta por estes autores apresenta a mais-valia de propor um modelo de análise às diferentes lógicas de julgamento. Baseando-se em autores ligados à Filosofia e à Filosofia Política, tais como Santo Agostinho, Adam Smith e Tomas Hobes, estes autores chegaram à conclusão de que os atores tendem a invocar princípios superiores de bem-comum, na argumentação expressa na arena pública, pelo facto de terem consciência de que os argumentos para se legitimarem precisam de invocar valores socialmente aceites em termos de generalidade.

Partimos do pressuposto que os atores se valem de diferentes lógicas para formularem o julgamento que apresentam no espaço público e que os dispositivos que estes acionam não se devem ao acaso. Pelo contrário, resultam de um processo reflexivo que estes atores realizam com vista alcançarem a legitimação da lógica de ação que pretender defender. ${ }^{27}$

Neste sentido, o ator ocupa um papel crucial na formulação do julgamento. Portanto, vale-se do exercício da racionalidade crítica para formular o seu julgamento, não aderindo cegamente às estruturas. Em nosso entender, o ator dispõe de um conjunto de valores morais, os quais lhe permitem não só avaliar a própria ação como a ação dos outros com que se relaciona. ${ }^{28}$

25 BOLTANSKI, L.; THÉVENOT, L. - De La Justification. Les Économies de La Grandeur. Paris: Éditions Gallimard, 1991.

26 BOLTANSKI, L.; THÉVENOT, L. - De La Justification. Les Économies de La Grandeur. Paris: Éditions Gallimard, 1991.

27 BOLTANSKI, L.; THÉVENOT, L. - De La Justification. Les Économies de La Grandeur. Paris: Éditions Gallimard, 1991.

28 GIDDENS, Anthony - As Consequências da Modernidade. Oeiras: Editora Celta, 2005. 
Com vista sustentar este modelo, pretendemos empregar as técnicas de análise qualitativa de dados, tanto na fase do levantamento como na fase do seu tratamento. A opção pelas técnicas de análise qualitativa pareceu-nos a mais adequada, pelo facto de pretenderemos analisar os documentos político-normativos da Segurança, tais como (Plano Nacional de Defesa e Estratégia de Defesa Nacional) e os relatórios das reuniões realizadas com os atores dos segmentos diplomático, estratégico e técnico-operacional destes sectores.

As técnicas a serem utilizadas na fase do levantamento de dados foram essencialmente a análise de conteúdo e a entrevista semi-estruturada, enquanto na fase do tratamento dos dados empregou-se a técnica da análise de conteúdo temática.

As entrevistas semi-diretivas foram realizadas a atores com funções de decisão nos segmentos diplomático, estratégico e técnico-operacional. Optou-se por esta técnica, em detrimento do questionário, pelo facto de nos permitir recolher o máximo de informação subjetiva da parte dos atores. ${ }^{29}$

$\mathrm{Na}$ fase do tratamento de dados, empregou-se essencialmente a técnica da análise de conteúdo temática. Selecionamos esta técnica, pelo facto de permitir a compreensão das categorias macro que compõem os sentidos atribuídos pelos atores à questão da cooperação na área da Segurança. ${ }^{30}$

A variedade de instituições e de atores contactados levou-nos a optar por uma técnica de abordagem denominada bola-de-neve, baseada sobretudo no índice da saturação das informações apreendidas. Esta técnica deixou de ser privilegiada quando as informações levantadas começaram a ser redundantes.

Sublinha-se que o segmento diplomático compreende as embaixadas dos países lusófonos com representação em Portugal. O segmento estratégico, por sua vez, compreende todos os gabinetes com responsabilidades no planeamento, coordenação e implementação de iniciativas no domínio da cooperação em Segurança entre países lusófonos. De uma forma sintetizada, poder-se-á dizer que o segmento técnico-operacional compreende as instituições com responsabilidades na operacionalização das medidas relacionadas com o reforço da cooperação em matéria de Segurança, propostas pelo segmento técnico-estratégico.

29 QUIVY, Raynond; CAMPENHOUDT, Luc Van - Manual de Investigação em Ciências Sociais. 2. ${ }^{a}$ ed. Lisboa: Gradiva, 1998.

30 QUIVY, Raynond; CAMPENHOUDT, Luc Van - Manual de Investigação em Ciências Sociais. 2. ${ }^{a}$ ed. Lisboa: Gradiva, 1998. 
Os discursos e as controvérsias da cooperação técnico-militar e técnico-policial entre Portugal, Angola e Brasil MÓNICA DE MELO FREITAS

GALILEU · e-ISSN 2184-1845 - Volume XX - Issue Fascículo 1 $1^{\text {st }}$ January Janeiro $-30^{\text {th }}$ June Junho 2019 - pp. 59-77

\section{Resultados da Investigação Empírica}

Entre Março de 2010 e Fevereiro de 2011, realizamos cerca de 17 entrevistas semi-directivas, a atores com funções de decisão nos segmentos diplomático, estratégico e técnico-operacional no sector da Segurança de Angola, Brasil e Portugal.

Procuramos, através das entrevistas que realizamos, perceber qual o ponto de situação da cooperação lusófona na área técnico-policial entre aqueles países, de forma a complementar as informações que levantamos na análise dos Planos Nacionais de Defesa e dos Conceitos Estratégicos de Defesa Nacional do Brasil e de Portugal.

A partir das referidas entrevistas pudemos verificar que existem essencialmente dois modelos de cooperação técnico-policial no espaço lusófono. Ou seja, um modelo que está relacionado à cooperação estabelecida entre Portugal e Brasil e um outro modelo referente à cooperação consolidada entre Portugal e PALOP ${ }^{31}$.

A cooperação técnico-policial existente entre Brasil e Portugal apresenta acordos formais e informais de cooperação, visto que se por um lado os acordos formais propiciam a realização de exercícios conjuntos, a externalização de competências técnicas especializadas e o intercâmbio de oficiais com vista a realização de formação, por outro lado, os acordos informais facilitam o intercâmbio de informações de elevado interesses às forças de segurança em áreas como ordem pública, tráfico de drogas, imigração ilegal, entre outras.

Já a cooperação técnico-policial existente entre Portugal e os PALOP fundamenta-se exclusivamente nos acordos formais de cooperação que são consolidados na área da formação. A par da formação, Portugal transfere para os PALOP, equipamentos e materiais para as respetivas forças de segurança, com vista elevar o nível de operacionalização e de eficiência destas.

Quanto ao futuro da(s) cooperação(es) consolidada(s) entre os países de expressão portuguesa na área técnico-policial, sublinha-se o facto da agenda do Ministério da Administração Interna de Portugal prever o reforço dos acordos de cooperação com o Brasil, principalmente em áreas como o combate à imigração ilegal e ao tráfico de drogas, a realização de exercícios conjuntos, o intercâmbio de experiências e boas práticas, além da assessoria técnica em manutenção de ordem pública em grandes eventos desportivos. Salienta-se ainda o facto da referida agenda prever o reforço dos acordos de cooperação na área da formação técnico-policial e da assessoria técnica com os países africanos de expressão portuguesa.

31 PALOP: Países de Língua Oficial Portuguesa. 
Os discursos e as controvérsias da cooperação técnico-militar e técnico-policial entre Portugal, Angola e Brasil MÓNICA DE MELO FREITAS

GALILEU - e-ISSN 2184-1845 - Volume XX - Issue Fascículo 1 - $1^{\text {st }}$ January Janeiro - 30th June Junho 2019 - pp. 59-77

\section{Considerações Finais}

A investigação realizada demonstrou que, em termos de dimensão e eficácia, a cooperação entre os países lusófonos, embora tenha raízes de natureza histórica, está longe de ser consensual. Alguns autores e atores entrevistados salientaram que a cooperação no espaço lusófono tem encontrado alguns entraves, entre os quais se sublinha a predominância dos interesses nacionais em detrimentos do interesses do coletivo destes países.

Associada a esta problemática de diferenças de visão e nível de ambição, acresce ainda o desnivelamento económico, institucional e científico entre os países da CPLP. O não terem sido ainda criadas estruturas comuns direcionadas para apoiar a cooperação técnico-policial entre os países lusófonos, releva como uma dificuldade adicional.

Conforme se pode constatar, os atores do sector da Segurança formularam os julgamentos relativos à cooperação técnico-policial, com base em princípios distintos quando foram confrontados. A ausência de consensos parece não se restringir apenas ao nível dos julgamentos. Pudemos igualmente constatar que os atores invocaram diferentes dispositivos de prova com vista suportarem às lógicas de justificação apresentadas relacionadas ao reforço da cooperação. Em nosso entender, os atores da Segurança demonstraram uma plasticidade incrivel no que concerne à construção de lógicas de julgamento, as quais vale a pena serem exploradas.

Embora consideremos relevantes as abordagens históricas e institucionais em que muitos autores enquadraram a cooperação, tencionamos enquadrar o nosso estudo na crise do sistema capitalista e nas alterações do Estado-Providência. As alterações ocorridas no interior do sistema capitalista têm pressionando cada vez mais os atores a justificarem a sua ação individual com base em princípios de bem comum. Neste sentido, acreditamos fazer sentido analisar a forma como os atores do sector da Segurança procuram fundamentar as suas práticas em princípios socialmente aceites do ponto de vista da generalidade, ou seja, do bem comum, com vista obterem a necessária legitimação.

Por fim, acreditamos que a compreensão dos processos de julgamento que os atores realizam nos sectores da Segurança e da Defesa, constitui um laboratório privilegiado para compreendermos as transformações que vêm ocorrendo no interior do sistema capitalista de Estado-Providência. 


\section{REFERÊNCIAS BIBLIOGRÁFICAS}

BOLTANSKI, L.; CHIAPELLO, E. - O Novo Espírito do Capitalismo. 1. ${ }^{a}$ ed. São Paulo: Martins Fontes, 2009.

BOLTANSKI, L.; THÉVENOT, L. - De La Justification. Les Économies de La Grandeur. Paris: Éditions Gallimard, 1991.

CPLP - Construindo a Comunidade. Europress: Lisboa, 2008.

EWALT, Jo Ann G. - Theories of Governance and New Public Management: Links to Understanding Welfare Policy Implementation. Eastern Kentuchky University. Newark, 2001.

GIDDENS, Anthony - As Consequências da Modernidade. Oeiras: Editora Celta, 2005.

MOREIRA, Adriano - Comunidade dos Países de Língua Portuguesa. Cooperação. Lisboa: Almedina, 2001.

QUIVY, Raynond; CAMPENHOUDT, Luc Van - Manual de Investigação em Ciências Sociais. 2. ${ }^{a}$ ed. Lisboa: Gradiva, 1998.

SILVESTRE, Hugo Marco C.; ARAÚJO, Joaquim Filipe F. E. - A gestão por Resultados no Sector Público: O caso dos Hospitais EPE, 2005. [Consultado em: Março de 2019]. Disponível em: https://www.repository. utl.pt/bitstream/10400.5/515/4/605.pdf.

TRIGILIA, Carlo - Economic Sociology: State, Market, and Society in Modern Capitalism. Oxford: Blackwell Publishers, 2002.

VENTURA, Elvira - Estudo da Responsabilidade Social no Campo das Organizações Bancárias. EBAPE (Escola Brasileira de Administração Pública e de Empresas). Tese apresentada à EBAPE para a obtenção do grau de doutor, 2005. 